\title{
Periprandial changes of the sympathetic-parasympathetic balance related to perceived satiety in humans
}

\author{
Lucien F. Harthoorn • Eric Dransfield
}

Accepted: 13 November 2007 / Published online: 19 December 2007

(C) The Author(s) 2007

\begin{abstract}
Food intake regulation involves various central and peripheral mechanisms. In this study the relevance of physiological responses reflecting the autonomic nervous system were evaluated in relation to perceived satiety. Subjects were exposed to a lunch-induced hunger-satiety shift, while profiling diverse sensory, physiological, and biochemical characteristics at 15 min intervals. Sensory ratings comprised questionnaires with visual analogues scales about their feeling of satiety, desire to eat, fullness, and hunger. Physiological characteristics included heart rate, heart rate variability, and blood pressure, while biochemical markers such as cortisol levels and $\alpha$-amylase activity were monitored in saliva. The four sensory ratings correlated with heart rate and salivary $\alpha$-amylase suggesting a higher sympathetic tone during satiety. Furthermore, heart rate variability was associated with age and waist-to-hip ratio and cortisol levels negatively correlated with body mass index. Finally, neither chewing nor swallowing contributed to a heart rate increase at food consumption, but orosensory stimulation, as tested with modified sham feeding, caused a partial increase of heart rate. In conclusion, after meal ingestion critical physiological alterations reveal a elevated sympathetic tone, which is a potential measure of satiety.
\end{abstract}

Keywords Eating $\cdot$ Heart rate $\cdot$ Human $\cdot$ Saliva $\cdot$ Satiation

L. F. Harthoorn $\cdot$ E. Dransfield

TI Food and Nutrition (WCFS), Wageningen, The Netherlands

L. F. Harthoorn ( $\square)$

Wageningen UR, Agrotechnology and Food Sciences Group, Centre for Innovative Consumer Studies, P.O. Box 17,

6700 AA Wageningen, The Netherlands

e-mail: lucien.harthoorn@wur.nl

\section{Introduction}

Regulation of food intake comprises both homeostatic and hedonic components controlled by hunger and satiety signals in both peripheral and central pathways. Afferent and most peripheral signals provide information about the body's nutritional state and the central nervous system mediates and integrates episodic hunger and satiety signalling towards a functional output that controls metabolism with accompanying behaviour (Schwartz et al. 2000). While communication between periphery and brain is crucial in coordinating integrative processes for metabolism, such signals can also be anticipatory as they can rise even before food is ingested through visual, auditory, and olfactory stimuli (Mattes 1997), or even appear, like insulin secretion, when no food was presented to naïve subjects (Bellisle et al. 1985).

In hunger and satiety signalling, endocrine systems and the autonomic nervous system (ANS), play crucial roles. The sympathetic (SNS) and parasympathetic nervous system (PNS), support distinct and opposite functions in alertness and physiology. They respond to changes in both the external and internal environments and are also important in regulation of metabolism and energy homeostasis (Tempel and Leibowitz 1994; Bray 2000). In relation to a hunger-satiety shift after food intake in humans, changes of the SNS and PNS activity can occur before those in nutritional hormone levels, as demonstrated by instant changes in the states of alertness (Craig and Richardson 1989; Geisler and Polich 1992; Holt et al. 1999), muscle sympathetic nerve activity (Fagius and Berne 1994), and cardiac output (Waaler et al. 1991; Waaler and Eriksen 1992), which may be part of cephalic phase responses (Mattes 1997; Nederkoorn et al. 2000). An inverse relationship of SNS activity and body fat emphasize the importance of the SNS in food 
intake, suggesting a role of $\beta$-adrenergic receptors in peripheral and central control of eating (Bray 2000). Tracking of ANS characteristics and how they are changing in relation to appetite and satiety helps to understand the role of the ANS in the context of food intake regulation, overweight and obesity.

The present study assessed whether time course and patterns of physiological responses in humans may serve as consistent characteristics of the SNS-PNS balance and indicate perceived satiety. We hypothesised that ANS characteristics are affected by satiety. Subjectively rated satiety, desire to eat, fullness, and hunger were evaluated over a session of $4.75 \mathrm{~h}$, including a lunch-induced hunger-satiety shift, while heart rate (HR), heart rate variability (HRV) and blood pressure were monitored. Cortisol levels and $\alpha$-amylase activity were also measured from the subject's saliva as two other determinants reflecting the SNS-PNS balance. Related to food intake, cortisol, as the end product of the hypothalamicpituitary-adrenal-axis, has a primary function in controlling nutrient ingestion and metabolism over the circadian cycle (Tempel and Leibowitz 1994), the hypothalamus is a key target for cortisol (Stricker-Krongrad and Beck 2002; Harthoorn et al. 2005), and adrenalectomy causes a reduction of food intake (Drazen et al. 2003, 2004). Salivary $\alpha$-amylase is a biomarker for SNS activity because it serves as a correlate of adrenergic activity under stress, and is predictive of plasma catecholamine levels (Chatterton et al. 1996; Rohleder et al. 2004). Finally, chewing, swallowing, and orosensory stimulation by food in a modified sham-feeding model were examined for a possible contribution to HR alterations.

\section{Methods}

Healthy subjects, 9 males and 9 females, aged between 23 and 63 years (average 42.9 years) participated in this study. Smokers and subjects with prescribed medication, except for contraceptives, and excessive weight loss during the last 3 months were excluded from participating in this study. The subjects were paid for their involvement and informed consent was obtained according to the guidelines of the Ethical Committee of Wageningen UR. Weight, height, and waist and hip circumferences, were measured while subjects wore light indoor clothing with emptied pockets and no shoes. To estimate body weight, $1 \mathrm{~kg}$ was subtracted from clothed body weight. Body mass index (BMI) was the weight divided by height squared. Waist circumference was measured at the level midway between the lower rib margin and the iliac crest, with participants in a standing position and breathing out gently. Hip circumference was measured at the level of the widest circumference over the greater trochanters. The waist-to-hip ratio (WHR) was calculated as waist circumference divided by hip circumference.
Design and procedure

Each subject was tested alone in a quiet furnished room with appropriate ventilation and lighting from 11:45 a.m. to 16:30 p.m. All subjects had their breakfast as usual at least $3 \mathrm{~h}$ before starting the test session. Subjects chose their lunch from a standard menu, which was served at exactly 12:30 p.m., and was finished within $20 \mathrm{~min}$. The lunch was ad libitum, and the left-over of each meal was weighed and calculated into energy content to calculate total intake. The meals eaten were between 2.5 and $3.3 \mathrm{MJ}$, which is about $30 \%$ of the recommended regular daily intake, and contained 15-20\%(energy) protein, 35-40\%(energy) fat, and $40-45 \%$ (energy) carbohydrates. The meals did not contain caffeine or capsaicin. During the session a Polar S810 device (Polar Electro Oy, Kempele, Finland) recorded beatby-beat periods (R-R intervals) continuously. Every 15 min systolic and diastolic blood pressure were measured by an OMRON M4-I fully automatic monitor (OMRON Healthcare Europe, Hoofddorp, The Netherlands), saliva was donated, and subjects were asked to rate "how satiated are you", "how is your desire to eat", "how full are you", and "how hungry are you", using 100-mm non-structured visual analogue line scales (VAS) all on one page and anchored at their ends by the descriptors "very little" and "very much" (Flint et al. 2000).

\section{HR and HRV}

For determination of $\mathrm{HR}$ and $\mathrm{HRV}$, individual datasets were obtained from the Polar S810 device. Data processing and analysis were performed by Polar Precision Performance software (version 4.00.020), based on the consecutive numbers of successive R-R intervals (ms) during the test session. HR was derived and expressed as beats/min of each successive $15 \mathrm{~min}$. Determining $\mathrm{R}-\mathrm{R}$ interval over 15 min allowed HR and HRV measurement with high (<3 ms) timing accuracy (Ruha et al. 1997). Power spectral analysis of HRV was computed from the R-R formats over data segments of $15 \mathrm{~min}$ each, with cubic interpolation for the $\mathrm{R}-\mathrm{R}$ series at $4 \mathrm{~Hz}$ and spectrum estimation based on fast Fourier transformation. The two main rhythmic oscillations in the R-R intervals were a high frequency (HF) component between 0.15 and $0.40 \mathrm{~Hz}$ synchronous to respiratory activity, and a low frequency (LF) component between 0.04 and $0.15 \mathrm{~Hz}$ related to vasomotor waves. For both LF and HF components, the centre frequency and associated power, i.e. area under the curves of individual components $\left(\mathrm{ms}^{2}\right)$, were calculated. The power in the HF band represents PNS activity, while the power in the LF band characterises SNS activity and part of the PNS activity (Berger et al. 1986; Pagani et al. 1986; Malliani et al. 1994; Perini and Veicsteinas, 2003). A reciprocal relation 
exists between the HF and LF rhythms from which an index characterising the SNS-PNS balance can be derived. The LF-to-HF ratio (\%) was determined for every $15 \mathrm{~min}$.

\section{Saliva biochemistry}

Every $15 \mathrm{~min}$ subjects chewed on a rolled $25-\mathrm{cm}^{2}$ sheet of parafilm (Parafilm ${ }^{\circledR} \mathrm{M}$ ) for up to $1 \mathrm{~min}$ and spat into a $12 \mathrm{ml}$ polystyrene tube (Greiner Bio-One, Kremsmünster, Austria). The saliva was immediately placed into a freezer at $-40^{\circ} \mathrm{C}$. For further biochemical analyses, saliva samples were centrifuged at $1,000 \mathrm{~g}$ for $2 \mathrm{~min}$. The salivary cortisol level was determined on $25 \mu \mathrm{l}$ of thawed saliva using a Cortisol Enzyme Immunoassay (EIA) Kit (DSL-10-67100) (Diagnostic Systems Laboratories DSL, Sinsheim, Germany) with an intra-assay variation between 1.9 and $4.8 \%$ and an inter-assay variation between 3.8 and $7.2 \%$. Determination of in vitro salivary $\alpha$-amylase activity was performed on $10 \mu \mathrm{l}$ of saliva by means of an $\alpha$-Amylase Kinetic Reaction Kit (Salimetrics LLC, State College, PA, USA) using 2-chloro- $p$-nitrophenol linked with maltotriose as chromagenic substrate and measured at $405 \mathrm{~nm}$. The intra-assay variation was between 2.5 and $7.2 \%$, and the inter-assay variation between 3.6 and $5.8 \%$.

Oral activities and orosensory stimulation

Of the 18 subjects, 6 men and 6 women (BMI between 21.5 and 28.4), were exposed to distinct sessions of $15 \mathrm{~min}$ in which different oral activities and processing were examined for their influence on HR. Baseline of HR was measured for $15 \mathrm{~min}$. Sessions consisted of either chewing on parafilm for $15 \mathrm{~min}$, drinking $200 \mathrm{ml}$ of water during the first $5 \mathrm{~min}$ of the $15 \mathrm{~min}$ session, consuming $200 \mathrm{ml}$ of yoghurt-drink (Friesland Foods, The Netherlands, 1.0 MJ, containing: $3.0 \%(\mathrm{w} / \mathrm{w})$ protein, $17 \%(\mathrm{w} / \mathrm{w})$ carbohydrates, $16 \%(\mathrm{w} / \mathrm{w})$ sugars, and $3.0 \%(\mathrm{w} / \mathrm{w})$ fat) during the first $5 \mathrm{~min}$ of a 15 min session, or modified sham feeding of this yoghurt-drink, a "chew and spit" technique in which foods are smelled, chewed, and tasted, but not swallowed (Robertson et al. 2001), during 5 min of the 15 min session. HR was monitored over data segments for resting and chewing periods and of $5 \mathrm{~min}$ periods for drinking and sham feeding.

\section{Data analyses}

Data are expressed as the mean \pm SEM, unless otherwise specified. Of each measure and per time point, values were averaged over 18 subjects. Correlations were calculated between each of the four VAS ratings and HR, LF-to-HF ratio, blood pressure, cortisol, and $\alpha$-amylase across the 20 time points of the session. Across subject correlations were done between age, BMI, WHR and both preprandial and postprandial levels of HR, LF-to-HF ratio, blood pressure, cortisol, and $\alpha$-amylase per individual. For statistical assessment, postprandial values were compared to preprandial level and differences were established with repeated measures analysis of variance (ANOVA). Differences with $P$ values of 0.05 or less were considered to be statistically significant. All data were analysed by using Statistica (version 6.0; StatSoft, Tulsa, OK, USA).

\section{Results}

Mean BMI was $25.0 \pm 3.5 \mathrm{~kg} / \mathrm{m}^{2}$ and mean WHR was $0.89 \pm 0.07$ (Table 1). As shown in Fig. 1, prior to lunch, desire to eat and hunger ratings increased from about 35 to $70 \mathrm{~mm}$. Satiety ratings decreased from 50 to $35 \mathrm{~mm}$, whilst fullness scores did not change markedly during the preprandial period. Lunch induced changes in all four sensory ratings followed by a steady reduction of these shifts over time. Average ratings of satiety and fullness were increased over $30 \mathrm{~min}$ by about $40 \mathrm{~mm}$, while desire to eat and hunger ratings decreased to about $10 \mathrm{~mm}$. After these shifts, ratings gradually declined to about preprandial scores over the next $4 \mathrm{~h}$.

HR, HRV, and blood pressure

Shortly after starting the lunch, HR increased by $10 \pm 2.5 \%$ $(P<0.02)$ for about $20 \mathrm{~min}$, and then decreased for a following $30 \mathrm{~min}$ (Fig. 2a). Forty-five to $50 \mathrm{~min}$ after starting the lunch, a second and more prolonged increase of HR was found $(P<0.02)$ that lasted at least $1 \mathrm{~h}$.

In the HRV a bi-phasic trend of postprandial fluctuations for LF-to-HF ratio was found, but these were not significantly different from the preprandial level (Fig. 2b). Systolic pressure demonstrated minor fluctuations during the session, which were not significantly different from before

Table 1 Anthropometric values for 18 subjects and session means of physiological characteristics

\begin{tabular}{lll}
\hline & Average $\pm \mathrm{SD}$ & Range \\
\hline Age (years) & $42.9 \pm 13.0$ & $23-63$ \\
Body mass index $\left(\mathrm{kg} / \mathrm{m}^{2}\right)$ & $25.0 \pm 3.5$ & $21.5-36.1$ \\
Waist-to-hip ratio & $0.89 \pm 0.07$ & $0.77-1.00$ \\
Heart rate (beats/min) & $75.3 \pm 7.8$ & $63.3-89.3$ \\
LF-to-HF ratio $(\%)$ & $409 \pm 282$ & $103-1,182$ \\
Blood pressure $(\mathrm{mmHg})$ & & \\
Systolic & $126 \pm 13$ & $107-150$ \\
Diastolic & $78 \pm 10$ & $56-95$ \\
Salivary cortisol $(\mathrm{nmol} / \mathrm{l})$ & $14.2 \pm 6.1$ & $6.0-30.3$ \\
Salivary $\alpha$-amylase $(\mathrm{U} / \mathrm{ml})$ & $139 \pm 69$ & $14-263$ \\
\hline
\end{tabular}



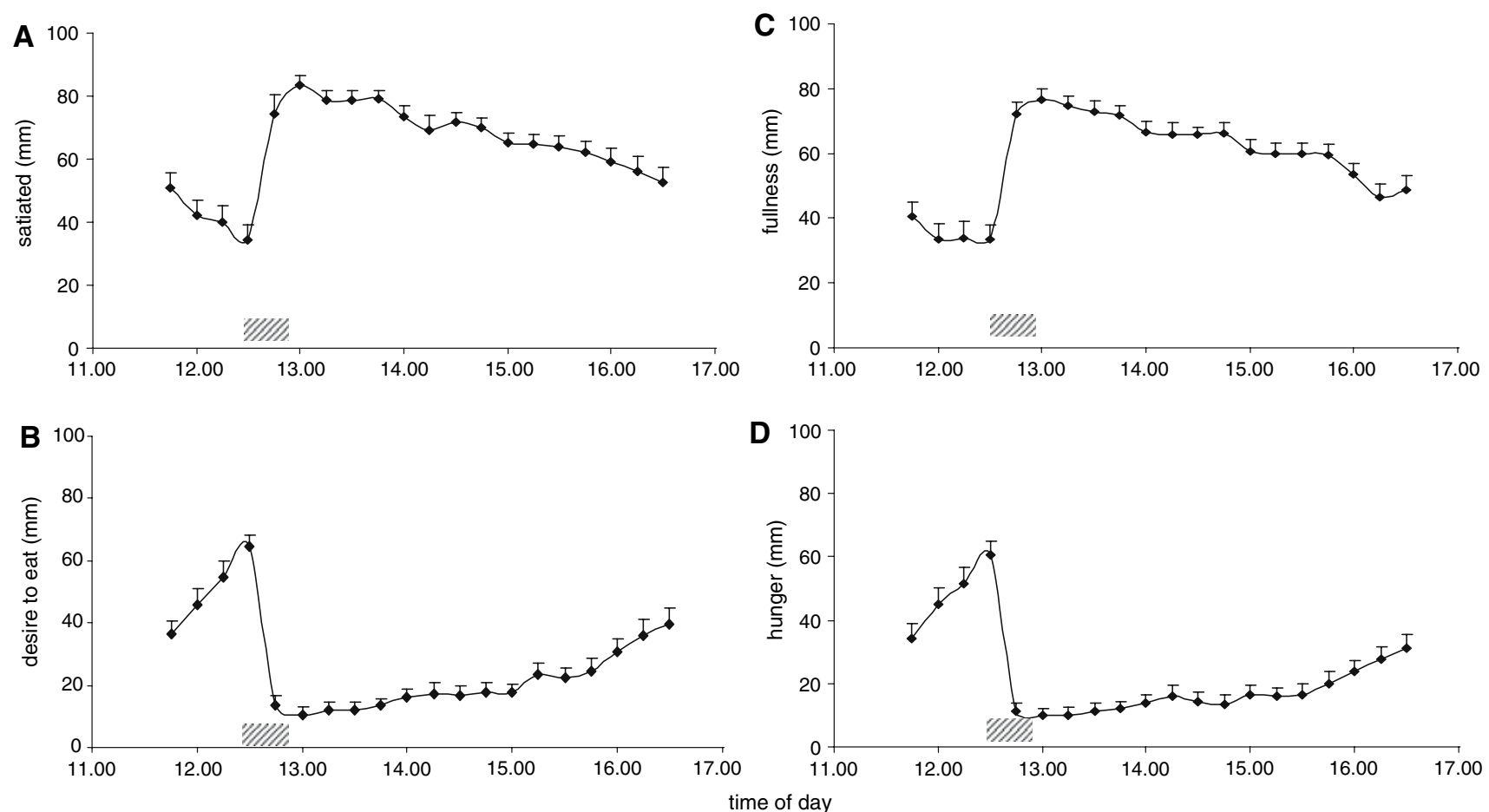

Fig. 1 Satiety (a), desire to eat (b), fullness (c), and hunger (d) rated on VAS for 18 subjects. Bars are SEM. Grey-shaded bar represents lunch

lunch, however, diastolic pressure showed a postprandial decrease $(P<0.02)$ (Fig. 2c).

\section{Saliva biochemistry}

Salivary cortisol levels were high at the beginning of the session, followed by a gradual decrease during the day (Fig. 3a) without any significant influences of the lunch. Similar to the bi-phasic increase of HR, in vitro salivary $\alpha$ amylase activity displayed a similar pattern over the session (Fig. 3b). An increase of $60 \pm 15 \%$ as compared to preprandial level in $\alpha$-amylase activity was observed $(P<0.01)$ early after starting the lunch meal. A second and more lengthened increase of $\alpha$-amylase activity was demonstrated between 1 and $3 \mathrm{~h}$ after starting the lunch $(P<0.01)$.

\section{Sensory ratings and ANS characteristics}

Correlations were found between VAS satiety, desire to eat, fullness, and hunger. Variations in satiety rating across time correlated with fullness $(r=0.99, P<0.001)$, desire to eat ( $r=-0.97, P<0.001)$, and hunger $(r=0.96, P<0.001)$. Desire to eat was correlated to fullness $(r=-0.96$, $P<0.001)$ and hunger rating $(r=0.99, P<0.001)$, and fullness rating was correlated with hunger $(r=-0.95$, $P<0.001)$.

HR showed correlations to satiety ( $r=0.74, P<0.001)$, desire to eat $(r=-0.74, P<0.001)$, fullness $(r=0.74$,
$P<0.001)$, and hunger $(r=-0.66, P<0.01)$. LF-to-HF ratio was not significantly correlated to the four sensory ratings. Although systolic pressure was not associated to any of the sensory ratings, diastolic pressure showed correlations to satiety $(r=-0.48, \quad P<0.05)$, desire to eat $(r=0.53, P<0.05)$, fullness $(r=-0.50, P<0.05)$, and hunger $(r=0.58, P<0.01)$. Salivary cortisol levels were not significantly correlated with any of the sensory ratings, whereas salivary $\alpha$-amylase was correlated to satiety ( $r=0.78, P<0.001)$, desire to eat $(r=-0.83, P<0.001)$, fullness $(r=0.80, P<0.001)$, and hunger $(r=-0.83$, $P<0.001)$.

Anthropometrics and physiological responses

A correlation was found between age and both preprandial and postprandial LF-to-HF ratio $(r=0.55, P<0.02$ and $r=0.52, P<0.05$, respectively) and age and postprandial HR $(r=0.49, P<0.05)$. WHR and postprandial LF-to-HF ratio appeared to be correlated $(r=0.55, P<0.02)$, but this relation was also found to be mediated by age. Preprandial cortisol levels were associated to BMI $(r=-0.47$, $P<0.05)$.

Oral activities and orosensory stimulation

Chewing, swallowing and orosensory stimulation by food in a modified sham-feeding model were examined for their possible effect on instant increases of HR. Neither chewing 

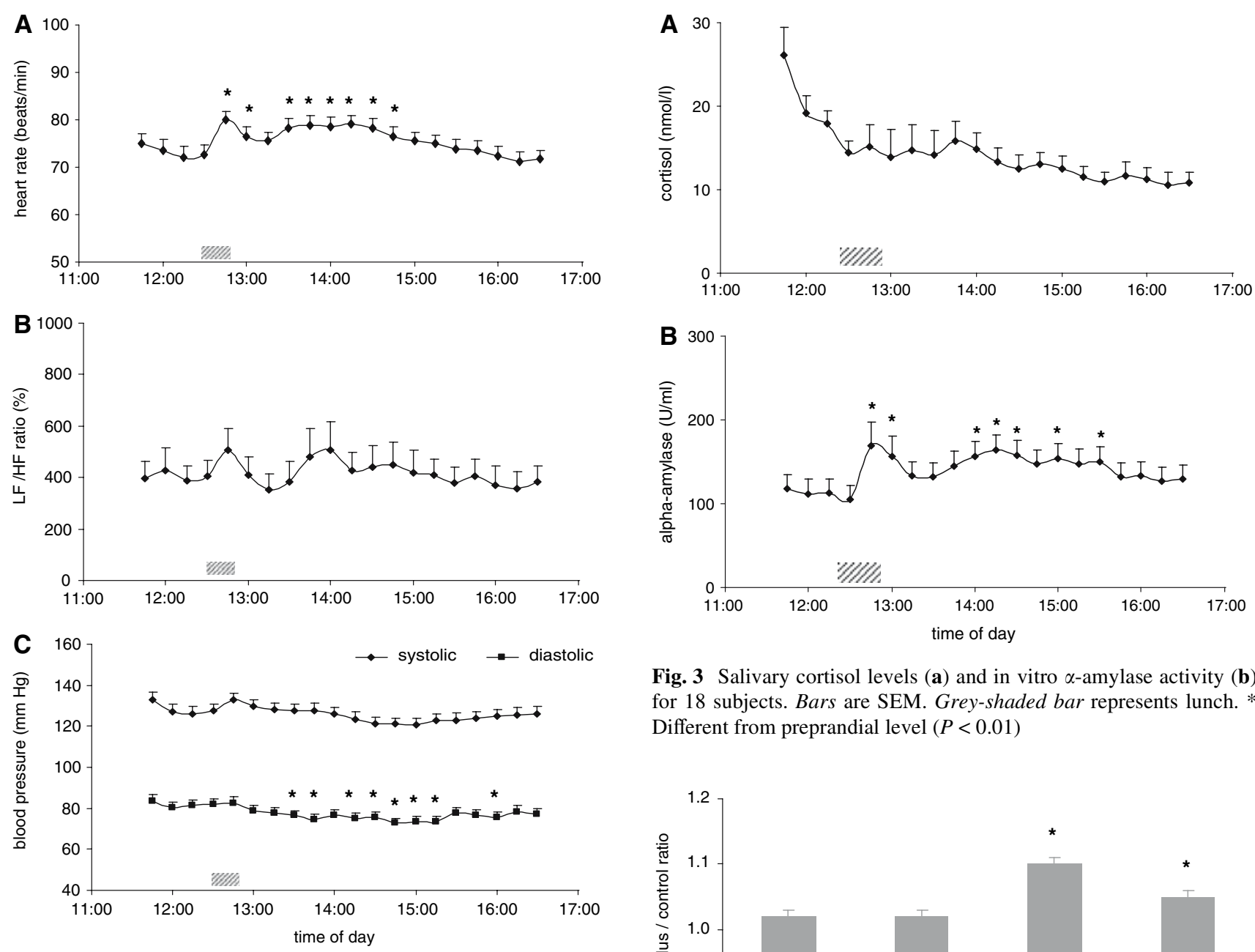

Fig. 3 Salivary cortisol levels (a) and in vitro $\alpha$-amylase activity (b) for 18 subjects. Bars are SEM. Grey-shaded bar represents lunch. * Different from preprandial level $(P<0.01)$

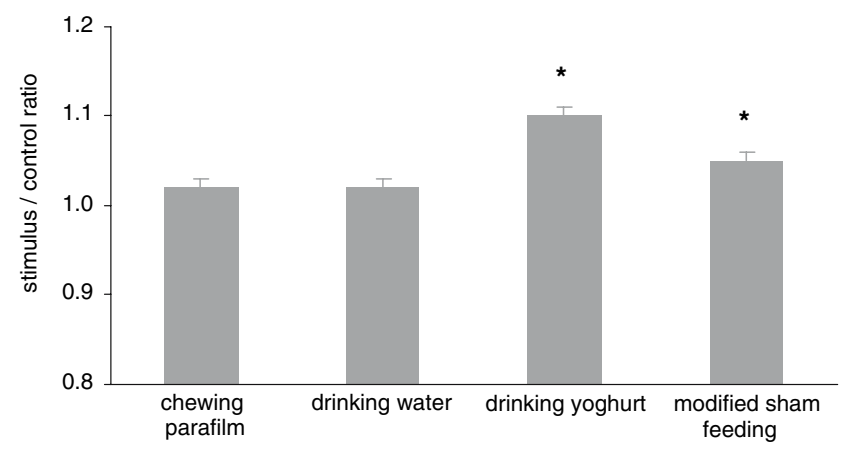

on parafilm nor drinking of water showed any increase of HR in comparison to baseline (Fig. 4). Drinking $200 \mathrm{ml}$ of yoghurt, which was without chewing, increased HR about $10 \%(P<0.01)$. This was a similar increase as under the lunch fed conditions. Finally, orosensory stimulation by the same type of yoghurt in sham feeding way increased HR about 5\% $(P<0.01)$.

\section{Discussion}

Sensory ratings scales for satiety, desire to eat, fullness, and hunger were used in combination with measures to assess the relevance and temporal pattern of responses reflecting the sympathetic-parasympathetic (SNS-PNS) balance in relation to perceived satiety in humans.

Satiety and hunger are often interpreted as being reciprocal, although they are mediated and signalled by different mechanisms, in which leptin, insulin, and cholecystokinin

Fig. 4 HR during chewing on parafilm, drinking water or yoghurt, and modified sham feeding with the same yoghurt-drink, expressed as stimulus-to-control ratio in relation to baseline for HR. Both consumption of yoghurt-drink and modified sham feeding of the yoghurt caused an increase in HR $(P<0.01)$. Bars represent SEM for 12 subjects

are important (Schwartz et al. 2000). For this reason several rating scales were used about feelings of satiety and hunger. Over a 4.75-h test session, including a lunch-induced hunger-satiety shift, all four VAS ratings showed consistent changes. The temporal profile of satiety rating was paralleled by fullness and inversely related to desire to eat and hunger ratings. Preprandially, increases of desire to eat and hunger ratings were larger than decreases of satiety and fullness ratings. Ingestion of a standard meal of 2.5-3.3 MJ changed all four VAS ratings $40-60 \mathrm{~mm}$, but with regard to the lunch-induced hunger-satiety shift, changes in desire to eat and hunger ratings were found to be larger than the 
changes of ratings of satiety and fullness. This suggests that ratings of "desire to eat" and "hunger" are more sensitive to the evaluation of appetite periprandially than ratings of "satiety" and "fullness". Sensory ratings tracked over time and combined with food intake demonstrated a gradual recovery to preprandial rating scores over about $4 \mathrm{~h}$ after meal consumption. This might reflect the gastrointestinal changes and processes over the same time that affect appetite. Although, differences may result from different types of food intake or different types of satiety measurements, recovery time also depends on sensory attributes (De Graaf 1993). The finding of a similar 4-h recovery time for all four sensory descriptors used, appears to be consistent following different types of meals (Green et al. 1997; Erdmann et al. 2004), and different rating techniques (Stubbs et al. 2001).

Physiological responses reflecting the SNS-PNS balance were simultaneous to altered patterns of perceived satiety. In this food-related context, these ANS characteristics not only provide additional insights into the integration of central and peripheral regulatory processes for metabolism, but also render a potential measure of satiety in humans.

Both the SNS and PNS are segmented multifunctional systems, which can be evaluated in several ways (Morrison 2001). Changes in HR, HRV, and blood pressure are some of the variables that can be used to assess the SNS-PNS balance, in which a higher HR and cardiovascular load and output is typified by a higher SNS-PNS ratio. High salivary $\alpha$-amylase levels are indicating a higher sympathetic tone, are predictive of high plasma catecholamine levels, and are reduced by adrenergic beta-blockers (Speirs et al. 1974; Chatterton et al. 1996). The SNS and PNS regulate processes and metabolic pathways important for recovery and energy homeostasis (Bray 2000; Szekely 2000). The changes of the SNS-PNS balance, therefore, are relevant to satiety and may occur before those in circulating hormones that stimulate or inhibit food intake. With regard to the effects of food intake on appetite, two distinct phases have been considered within the postulated "satiety cascade", called "satiation" and "satiety", the first defined as the process which develops during eating and which brings eating to end, and the second defined as the state of inhibition over further eating (Green et al. 1997). This satiety cascade takes into account properties of food, physiological processing of nutrients that contribute to overall control of food intake, and also conceptualises differences between immediate postingestive effects and those produced later. The digestive period is divided into three to four phases depending on the site at which food acts to stimulate neural and endocrine organs, i.e. the cephalic and orosensory, gastric, and intestinal phases, which are sequential and follow on the progression of a meal.

Both short- and long-term autonomic alterations occur towards a high sympathetic tone after a meal based on increases of HR and salivary $\alpha$-amylase. The short-term increases may belong to cephalic and orosensory phase responses, whereas the long-term increases cohere to the gastrointestinal mechanisms. While the importance of $\alpha$ amylase is on starch digestion, the association of both HR and $\alpha$-amylase with the VAS ratings show the possibility of measures for perceived satiety. Moreover, HR and $\alpha$-amylase have a recovery over about $4 \mathrm{~h}$ after a meal. Further, a diastolic blood pressure decline might characterize satiety, however, with weaker correlations. The haemodynamic changes illustrate that eating places demand on the cardiovascular system, most presumably specifically on the visceral compartment of the body. A postprandial increase in HR points to enhanced cardiac output, while a lower blood pressure during a high feeling of satiety may indicate a lower systemic resistance especially to visceral parts of the body, which results in a higher mesenteric blood flow (Jager et al. 1986), and may influence postprandial behaviour. The LF-to-HF ratio showed a similar bi-phasic trend as HR and salivary $\alpha$-amylase, however, it was a less consistent measure of SNS-PNS balance. In addition, a postprandial bi-phasic SNS predominance indicates immediate triggering of cephalic or orosensory responses and the more gradual activation of metabolic mechanisms within time frames coherent to the putative distinction between "satiety" and "satiation" (Green et al. 1997). The instant increase of HR with food intake can be part of a cephalic phase response triggered by oral physical activity, non-metabolic food cues, or sensory perception. Neither chewing, swallowing, nor water intake were responsible for a changed sympathetic tone as indicated by HR, however, orosensory stimulation with modified sham feeding enhanced HR to about half of the increase that was reached after intake of a meal. An instant increase in HR is, thus, induced in the oral cavity most presumably initiated by perception of taste, flavour, or energy-rich substrates. An alternative explanation for the bi-phasic effect on a higher SNSPNS balance is that the decrease in HR for about $30 \mathrm{~min}$ after finishing food intake is caused by inhibition of autonomic functioning. The satiety hormones cholecystokinin, glucagon-like peptide 1 , and gastric inhibitory peptide could be involved as their release from the gastrointestinal tract in response to eating (Matzinger et al. 2000; Burcelin 2005) inhibit autonomic functioning at the central level as demonstrated in rodents, where cholecystokinin inhibites brainstem presympathetic neurons and reduces HR (Sartor and Verberne 2002; Fan et al. 2004).

Aside from the close correlation between SNS and PNS balance and perceived satiety in a periprandial period, there is an inverse relationship between SNS activity and obesity, consistent with that most types of obesity are associated with low sympathetic activity (Bray 1991). Further personal characteristics like age, BMI, and WHR, were associated 
with the ANS characteristics. In addition to BMI as a marker of overweight, WHR serves as indicator of fat storage in abdominal depots. A negative correlation between salivary cortisol and BMI was found. The role of cortisol in obesity is complex with both high and low cortisol secretion patterns (Björntorp and Rosmond 2000). Cortisol is higher in subjects with the night-eating syndrome (Birketvedt et al. 1999) and binge eating disorder and bulimia nervosa (Gluck et al. 2004). In overweight subjects, a hypoactive hypothalamic-pituitary-adrenal-axis, not knowing whether it is cause or consequence of a dysregulated SNS, may contribute to greater hunger and over-consumption. A mechanism of hypothalamic-pituitary-adrenal-axis inhibition is described in rats, showing a negative feedback of visceral fat on the hypothalamus that lowers cortisol levels (Dallman et al. 2003, 2004; La Fleur et al. 2005).

In conclusion, within a periprandial context a high sympathetic tone is a potential measure of satiety in humans, and activation of the SNS might be a satiety system, which may also help regulation of food intake and energy expenditure from body fuel stores. HR and salivary $\alpha$-amylase may be implemented to measure satiety in eating disorders and overweight.

Acknowledgments This study was financially supported by DiOGenes. DiOGenes is the acronym of the project "Diet, Obesity and Genes" supported by the European Community (Contract no. FP6-FOOD-CT2005-513946). The Parties of the project are listed on the web site of the project (http://www.diogenes-eu.org/). We thank Linda Huntjens for recruiting the subjects and Pieter Vereijken for his advise on statistical analyses. Drs. Harold Bult and Rene A. de Wijk are gratefully acknowledged for their valuable comments on the manuscript.

Open Access This article is distributed under the terms of the Creative Commons Attribution Noncommercial License which permits any noncommercial use, distribution, and reproduction in any medium, provided the original author(s) and source are credited.

\section{References}

Bellisle F, Louis-Sylvestre J, Demozay F, Blazy D, Magnen J (1985) Cephalic phase of insulin secretion and food stimulation in humans: a new perspective. Am J Physiol Endocrinol Metab 249:E639-E645

Berger RD, Akselrod S, Gordon D, Cohen RJ (1986) An efficient algorithm for spectral analysis of heart rate variability. IEEE T Biomed Eng 33:900-904

Birketvedt GS, Florholmen J, Sundsfjord J, Østerud B, Dinges D, Bilker W, Stunkard A (1999) Behavioral and neuroendocrine characteristics of the night-eating syndrome. JAMA 282:657-663

Björntorp P, Rosmond R (2000) Obesity and cortisol. Nutrition 16:924-936

Bray GA (1991) Obesity, a disorder of nutrient partitioning: the MONA LISA hypothesis. J Nutr 121:1146-1162

Bray GA (2000) Reciprocal relation of food intake and sympathetic activity: experimental observations and clinical implications. Int J Obes 24:S8-S17

Burcelin R (2005) The incretins: a link between nutrients and well-being. Br J Nutr 93:S147-S156
Chatterton RT, Vogelsong KM, Lu YC, Ellman AB, Hudgens GA (1996) Salivary alpha-amylase as a measure of endogenous adrenergic activity. Clin Physiol 16:433-448

Craig A, Richardson E (1989) Effects of experimental and habitual lunch- size on performance, arousal, hunger and mood. Int Arch Occup Environ Health 61:313-319

Dallman MF, Pecoraro N, Akana SF, La Fleur SE, Gomez F, Houshyar H, Bell ME, Bhatnagar S, Laugero KD, Manalo S (2003) Chronic stress and obesity: a new view of "comfort food". PNAS 100:11696-11701

Dallman MF, La Fleur SE, Pecoraro NC, Gomez F, Houshyar H, Akana SF (2004) Minireview: Glucocorticoids-food intake, abdominal obesity, and wealthy nations in 2004. Endocrinology 145:2633-2638

De Graaf C (1993) The validity of appetite ratings. Appetite 21:156-160

Drazen DL, Wortman MD, Schwartz MW, Clegg DJ, Van Dijk G, Woods SC, Seeley RJ (2003) Adrenalectomy alters the sensitivity of the central nervous system melanocortin system. Diabetes 52:2928-2934

Drazen DL, Coolen LM, Strader AD, Wortman MD, Woods SC, Seeley RJ (2004) Differential effects of adrenalectomy on melaninconcentrating hormone and orexin a. Endocrinology 145:34043412

Erdmann J, Topsch R, Lippl F, Gussmann P, Schusdziarra V (2004) Postprandial response of plasma ghrelin levels to various test meals in relation to food intake, plasma insulin, and glucose. J Clin Endocrinol Metab 89:3048-3054

Fagius J, Berne C (1994) Increase in muscle nerve sympathetic activity in humans after food intake. Clin Sci 86:159-167

Fan W, Ellacot KL, Halatchev IG, Takahashi K, Yu P, Cone RD (2004) Cholecystokinin-mediated suppression of feeding involves the brainstem melanocortin system. Nat Neurosci 7:335-336

Flint A, Raben A, Blundell JE, Astrup A (2000) Reproducibility, power and validity of visual analogue scales in assessment of appetite sensations in single test meal studies. Int J Obes 24:38-48

Geisler MW, Polich J (1992) P300, food consumption, and memory performance. Psychophysiology 29:76-85

Gluck ME, Geliebter A, Hung J, Yahav E (2004) Cortisol, hunger, and desire to binge eat following a cold stress test in obese women with binge eating disorder. Psychosom Med 66:876-881

Green SM, Delargy HJ, Joanes D, Blundell JE (1997) A satiety quotient: a formulation to assess the satiating effect of food. Appetite 29:291-304

Harthoorn LF, Sañé A, Nethe M, Van Heerikhuize JJ (2005) Multitranscriptional profiling of melanin-concentrating hormone and orexin-containing neurons. Cell Mol Neurobiol 25:1209-1223

Holt SH, Delargy HJ, Lawton CL, Blundell JE (1999) The effects of high-carbohydrate vs high-fat breakfasts on feelings of fullness and alertness, and subsequent food intake. Int J Food Sci Nutr 50:13-28

Jager K, Bollinger A, Valli C, Ammann R (1986) Measurement of mesenteric blood flow by duplex scanning. J Vasc Surg 3:462-469

La Fleur SE, Houshyar H, Roy M, Dallman MF (2005) Choice of lard, but not total lard calories, damps adrenocorticotropin responses to restraint. Endocrinology 146:2193-2199

Malliani A, Pagani M, Lombardi F (1994) Physiology and clinical implications of variability of cardiovascular parameters with focus on heart rate and blood pressure. Am J Cardiol 73:3C-9C

Mattes RD (1997) Physiologic responses to sensory stimulation by food: nutritional implications. J Am Diet Assoc 97:406-413

Matzinger D, Degen L, Drewe J, Meuli J, Duebendorfer R, Ruckstuhl N, D'Amato M, Rovati L, Beglinger C (2000) The role of long chain fatty acids in regulating food intake and cholecystokinin release in humans. Gut 46:688-693

Morrison SF (2001) Differential control of sympathetic outflow. Am J Physiol Regul Integr Comp Physiol 281:R683-R698 
Nederkoorn C, Smulders FT, Jansen A (2000) Cephalic phase responses, craving and food intake in normal subjects. Appetite 35:45-55

Pagani M, Lombardi F, Guzzetti S, Rimoldi O, Furlan R, Pizzinelli P, Sandrone G, Malfatto G, Dell 'Orto S, Piccaluga E, Turiel M, Baselli G, Cerutti S, Malliani A (1986) Power spectral analysis of heart rate and arterial pressure variabilities as a marker of sympatho-vagal interaction in man and conscious dog. Circ Res 59:178-193

Perini R, Veicsteinas A (2003) Heart rate variability and autonomic activity at rest and during exercise in various physiological conditions. Eur J Appl Physiol 90:317-325

Robertson MD, Jackson KG, Williams CM, Fielding BA, Frayn KM (2001) Prolonged effects of modified sham feeding on energy substrate mobilization. Am J Clin Nutr 73:111-117

Rohleder N, Nater UM, Wolf JM, Ehlert U, Kirschbaum C (2004) Psychosocial stress-induced activation of salivary alpha-amylase: an indicator of sympathetic activity? Ann NY Acad Sci 1032:258-263

Ruha A, Sallinen S, Nissila S (1997) A real-time microprocessor ORS detector system with a 1-ms timing accuracy for the measurement of ambulatory HRV. IEEE T Bio-med Eng 44:159-167

Sartor DM, Verberne AJ (2002) Cholecystokinin selectively affects presympathetic vasomotor neurons and sympathetic vasomotor outflow. Am J Physiol Regul Integr Comp Physiol 282:R1174R1184
Schwartz MW, Woods SC, Porte D, Seeley RJ, Baskin DG (2000) Central nervous system control of food intake. Nature 404:661671

Speirs RL, Herring J, Cooper D, Hardy CC, Hind CRK (1974) The influence of sympathetic activity and isoprenaline on the secretion of amylase from the human parotid gland. Arch Oral Biol 19:747752

Stricker-Krongrad A, Beck B (2002) Modulation of hypothalamic hypocretin/orexin mRNA expression by glucocorticoids. Biochem Biophys Res Commun 296:129-133

Stubbs RJ, Hughes DA, Johnstone AM, Rowley E, Ferris S, Elia M, Stratton R, King N, Blundell JE (2001) Description and evaluation of a Newton-based electronic appetite rating system for temporal tracking of appetite in human subjects. Physiol Behav 72:615-619

Szekely M (2000) The vagus nerve in thermoregulation and energy metabolism. Auton Neurosci 85:26-38

Tempel DL, Leibowitz SF (1994) Adrenal steroid receptors: interactions with brain neuropeptide systems in relation to nutrient intake and metabolism. J Neuroendocrinol 6:479-501

Waaler BA, Eriksen M (1992) Post-prandial cardiovascular responses in man after ingestion of carbohydrate, protein or fat. Acta Physiol Scand 146:321-327

Waaler BA, Eriksen M, Toska K (1991) The effect of meal size on postprandial increase in cardiac output. Acta Physiol Scand 142:33-39 